\title{
LIPID PROFILE AND RELATED FACTORS AMONG ADOLESCENTS IN AN URBAN SETTING IN SRI LANKA: THE SITUATION IN 2006
}

\author{
K. M. G. K. Bandara ${ }^{1}$, P. V. R. Kumarasiri ${ }^{2}$ and D. B. Nugegoda ${ }^{2}$, \\ ${ }^{1}$ Regional Health Training Centre, Kadugannawa, Sri Lanka \\ ${ }^{2}$ Department of Community Medicine, Faculty of Medicine, University of Peradeniya, Peradeniya, Sri \\ Lanka
}

Corresponding Author: Dr. K M G K Bandara; Email: uvindukm@yahoo.com

\begin{abstract}
Background: It is reported that high blood pressure, dyslipidaemia, impaired glucose tolerance, and obesity emerge during childhood and adolescence, often clustered together and lead to the occurrence of Cardio Vascular Diseases in later life.
\end{abstract}

Objectives: The present descriptive, cross sectional study was performed to describe the lipid profile, fasting sugar levels and related factors among adolescents in an urban setting in Sri Lanka.

Methods: Biochemical assessment of serum lipid and glucose levels was carried out among 440 randomly selected students between 14 to 15 years, studying in 30 public schools in the Kandy Municipal Council area. Behavioural and biological risk factors were assessed using selfadministered questionnaires and biochemical assessment and anthropometry were done using standard techniques

Results: The mean Fasting Blood Sugar (FBS) was $83.43 \mathrm{mg} / \mathrm{dl}$ and it was significantly higher among the male adolescents $(\mathrm{p}<0.001)$. The mean total cholesterol was $184.33 \mathrm{mg} / \mathrm{dl}$. The mean total cholesterol $(\mathrm{p}=0.002)$, triglycerides $(\mathrm{P}=0.362)$ and $\mathrm{LDL}(\mathrm{P}=0.044)$ were higher among female adolescents. The mean FBS, total cholesterol, triglyceride and LDL values were higher among overweight students than other students in both sexes $(P=0.039)$. Insufficiently active students had higher mean total cholesterol and LDL levels and lower HDL levels than active students.

Conclusions: The prevalence of high FBS levels was very low but the prevalence of dyslipidaemia was relatively high among adolescents. Overweight status and insufficient physical activity levels are associated with higher cholesterol levels.

\section{Introduction}

The incidence of Cardio Vascular Diseases (CVD) is increasing in many countries and it accounts for $29.6 \%$ of Non Communicable Diseases (NCD) burden in Sri Lanka ${ }^{(1)}$. Coronary Heart Disease (CHD) is estimated to be the leading CVD and it contributes to 7.2 million or $44 \%$ of total CVD deaths worldwide ${ }^{(2)}$. CHD has been the leading cause of hospital deaths in Sri Lanka since $1995^{(1)}$.

With the available evidence, it is now generally accepted that the risk of many NCDs is not only determined by risk factors in mid-adult life, but begins in childhood, adolescence or even earlier ${ }^{(3)}$. The World 
Health Organization (WHO) expert committee report shows that contrary to what was long assumed, high blood pressure, dyslipidaemia, impaired glucose tolerance and obesity emerge in childhood and adolescence, often leading to atherosclerosis and in many cases, diabetes within this age group itself (4). Atherosclerosis is the pathological process leading to CVD.

Studies have shown that the association between multiple CVD risk factors and atherosclerosis in children and young adults, and the extent of fatty streaks and fibrous plaques in the aorta and coronary arteries increased with age. Among the cardiovascular risk factors, dyslipidaemia was strongly associated with the extent of lesions in the aorta and coronary arteries $(5,6,7)$

Previous Sri Lankan studies done in the 1990s among adolescents and adults, have shown that the CVD risk factors including hypercholesterolemia were gradually increasing ${ }^{(8,9)}$.

Identification of modifiable risk factors for CVD in young people permits primary prevention of atherosclerosis during childhood or early adolescence. Therefore the present study was done with the objective of describing the status of lipid profiles and related factors among school going adolescents in an urban setting in Sri Lanka.

\section{Materials and Methods}

A school based cross sectional study was carried out from April to July 2006 among adolescents of ages 14 to 15 years studying in public schools of the Kandy Municipal Council (KMC) area.

Adolescents with a diagnosis of any chronic illness or physical abnormality and students with learning disability were excluded from the sample.

\section{Sample size and sampling technique}

This study was conducted on a selected sub group of a much larger study cohort selected to identify risk factors for CHD. Considering the cost of laboratory tests and logistics pertaining to collection and analysis of blood samples, the sample size was limited to $10 \%$ of those individuals who were selected for the CHD risk factor study. Sample size for the CHD risk factor study was calculated using a standard formula (Estimating a population proportion with specified relative precision) (10). The required sample size for CHD risk factor study was 4000 after corrections for design effects of cluster sampling. The adolescents of the study population were studying in 30 public schools. A representative sample of 440 students was selected for the analysis of lipid profile and fasting blood sugar levels after leaving a margin of $10 \%$ for non response. Systematic random sampling technique was used to obtain a sample of 440 adolescents.

\section{Study Instruments \\ Self-administered structured questionnaires}

Self administered pre-coded structured questionnaires were used to collect data on dietary habits and physical activity.

The quality of the diet was assessed in the form of a 20 item Food Frequency Questionnaire (FFQ) ${ }^{(11)}$. Based on the scoring system developed by an expert panel, diet was categorized into two categories, namely suboptimal and optimal.

The International Physical Activity Questionnaire (IPAQ) was used to assess the physical activity level of the participants. The IPAQ assesses vigorous and moderate physical activities in addition to the walking of an individual. These broad groups include all activities carried out for more than ten minutes at a time. Based on the criteria given by the IPAQ data management group, 
subjects were classified into three categories namely, insufficiently active, sufficiently active and highly active ${ }^{(12)}$.

The pre testing of the questionnaires was done among adolescents of the same age studying at an urban school in the Gampola Medical Officer of Health area.

\section{Anthropometric measurements}

Standing height to the nearest $0.5 \mathrm{~cm}$ and body weight with an accuracy of $+/-100 \mathrm{~g}$ were measured using standardized equipment. Standard procedures were followed when taking measurements.

Body Mass Index (BMI) was calculated and overweight status was defined according to age and sex specific reference cut off points given by World Health Organization ${ }^{(13)}$.

\section{Blood pressure measurements}

Blood Pressure (BP) was measured using a standard mercury gauge sphygmomanometer. Measurements were carried out according to the guidelines of the American Heart Association (14). Blood pressure levels were described based on the Fourth Report on the Diagnosis, Evaluation, and Treatment of High Blood Pressure in Children and Adolescents ${ }^{(15)}$.

\section{Serological investigation}

Fasting blood samples were drawn following 12 hours of fasting and analyzed at the Department of Biochemistry, Faculty of Medicine, University of Peradeniya. Fasting blood sugar levels and lipid profiles were described according to the American Heart Association guidelines for primary prevention of atherosclerotic cardiovascular diseases beginning in childhood. FBS level was defined as high if it was $>105 \mathrm{mg} / \mathrm{dl}$. Lipid levels were defined as high if the Total Cholesterol (TC) was > 200mg/dl, Low Density Lipoproteins (LDL) were $>130$ $\mathrm{mg} / \mathrm{dl}$ and Triglycerides (TG) were $>150$ mg/dl. High Density Lipoproteins (HDL) $<35 \mathrm{mg} / \mathrm{dl}$ was defined as low ${ }^{(16)}$.

\section{Data collection}

Two trained pre-intern medical officers and four field assistants assisted the Principal Investigator (PI) in data collection. Data collection was done at each selected school. Written consent was taken from parents of recruited students for collection of data and blood. The field investigators took anthropometric measurements and blood pressure measurements of the clusters of students prior to administering of questionnaires.

The PI and nursing officers collected blood samples on given dates at schools and transported to the laboratory within 2 hours of collection. A student was considered as a non respondent if absent for the contact.

Statistical analysis was performed using the Statistical Package for Social Sciences (SPSS 10.1). Univariate analysis was carried out to describe the data and bivariate analysis was performed to see the relationships between different $\mathrm{CHD}$ risk factors. The significance of these relationships was estimated by performing F-test and t- test.

Ethical clearance was obtained from the Ethical Review Committee of the Faculty of Medicine, University of Peradeniya.

\section{Results}

A total of 400 students (179 males and 221 females) participated in the study. Female adolescents had higher mean values for BMI, systolic blood pressure and diastolic blood pressure (Table 1).

The higher mean BMI and systolic blood pressure seen in females compared to males were statistically significant $(\mathrm{p}=0.042$ and $\mathrm{p}=0.001$ respectively). 
Table 1. Mean BMI, Systolic and Diastolic Blood Pressure according to sex

\begin{tabular}{lll}
\hline Characteristic & $\begin{array}{l}\text { Males } \\
(\mathbf{n = 1 7 9})\end{array}$ & $\begin{array}{l}\text { Females } \\
(\mathbf{n}=221)\end{array}$ \\
\hline BMI $\left(\mathbf{k g} / \mathbf{m}^{2}\right)^{*}$ & $18.2(3.1)$ & $18.8(2.9)$ \\
Systolic & $107.2(10.6)$ & $111.4(9.9)$ \\
BP(mmHg)* & & \\
Diastolic & $66.4(7.5)$ & $66.7(7.2)$ \\
BP(mmHg) & & \\
\hline
\end{tabular}

Results presented as mean (SD), abbreviations used BMI-Body Mass Index, BP-Blood Pressure

* Difference significant at $\mathrm{p}<0.05$ with $\mathrm{t}$ test

The mean TC was $181.4 \mathrm{mg} / \mathrm{dl}$ among males and $187.3 \mathrm{mg} / \mathrm{dl}$ among females $(\mathrm{p}=0.002)$ (Table 2). The mean TC, TG and LDL were higher among female students. Females also have significantly higher mean HDL levels $(\mathrm{p}=0.044)$.
Only $1.1 \%$ (95\% CI: $0.3-4.0)$ of the male and $1.0 \%$ (95\% CI: $0.2-3.2$ ) of the female students had high FBS levels of above 105 $\mathrm{mg} / \mathrm{dl}$ (Table 3). Among the students, $33.8 \%$ (95\% CI: 27.9-40.2) of females and $22.3 \%$ (95\% CI: 16.9-29.0) of males had TC levels above $200 \mathrm{mg} / \mathrm{dl}$, the normal level.

Six point one percent (95\% CI: $3.5-10.7)$ of the males and $4.5 \%$ (95\% CI: $2.5-8.1)$ of the females had elevated TG levels. Of the study group, $8.4 \%$ (95\% CI: 5.1-13.4) of the male students and $6.8 \%$ (95\% CI: 4.1-10.8) of the female students had HDL levels below normal. There were $26.8 \%$ (95\% CI: 20.933.7) male and $31.2 \%$ (95\% CI: 25.4-37.4) female students whose LDL levels were above the normal value.

The mean FBS, total cholesterol, triglyceride and LDL values were higher among overweight students than the other students in both sexes (Table 4).

Table 2. Distribution of mean fasting blood sugar and blood lipid levels of the study population by sex.

\begin{tabular}{|c|c|c|c|c|c|}
\hline \multirow{2}{*}{$\begin{array}{l}\text { Fasting blood sugar (FBS) } \\
\text { and lipid profile (mg/dl) }\end{array}$} & \multicolumn{2}{|c|}{ Males $(n=179)$} & \multicolumn{2}{|c|}{ Females $(n=221)$} & \multirow{2}{*}{ Sig.* } \\
\hline & Mean & SD & Mean & SD & \\
\hline FBS & 83.43 & 9.14 & 80.08 & 8.59 & $P<0.001$ \\
\hline Total cholesterol & 181.41 & 24.27 & 187.25 & 26.43 & $P=0.022$ \\
\hline Triglycerides & 87.68 & 35.04 & 90.67 & 29.35 & $\mathrm{P}=0.362$ \\
\hline HDL & 48.24 & 10.37 & 50.29 & 9.68 & $P=0.044$ \\
\hline LDL & 114.92 & 24.79 & 119.08 & 22.63 & $\mathrm{P}=0.083$ \\
\hline Total CHO/HDL CHO ratio & 3.91 & 1.06 & 3.81 & 0.81 & $\mathrm{P}=0.285$ \\
\hline
\end{tabular}

$* \mathrm{t}$ - test was performed to test the level of significance.

Table 3. Distribution of study population according to normal and high fasting blood sugar and lipid levels by sex.

\begin{tabular}{|c|c|c|c|c|c|c|}
\hline \multirow{2}{*}{$\begin{array}{l}\text { Fasting blood } \\
\text { sugar(FBS) and } \\
\text { blood lipids }\end{array}$} & \multicolumn{2}{|c|}{ Males $(n=179)$} & \multicolumn{2}{|c|}{ Females $(n=221)$} & \multicolumn{2}{|c|}{ Total (400) } \\
\hline & $\begin{array}{l}\text { Normal } \\
\text { no. }(\%)\end{array}$ & $\begin{array}{l}\text { High } \\
\text { no. }(\%)\end{array}$ & $\begin{array}{l}\text { Normal } \\
\text { no. }(\%)\end{array}$ & $\begin{array}{c}\text { High } \\
\text { no. }(\%)\end{array}$ & $\begin{array}{l}\text { Normal } \\
\text { no. }(\%)\end{array}$ & $\begin{array}{l}\text { High } \\
\text { no. }(\%)\end{array}$ \\
\hline FBS & $177(98.9)$ & $2 \quad(1.1)$ & $219(99.0)$ & $2 \quad(1.0)$ & $(99.0)$ & $4(1.0)$ \\
\hline Total cholesterol & $139(77.7)$ & $40(22.3)$ & $146(66.1)$ & $75(33.8)$ & 1.3) & $115(28.7)$ \\
\hline Triglycerides & $168(93.9)$ & 11 (6.1) & $211(95.5)$ & $10 \quad(4.5)$ & $379(94.8)$ & $21(5.2)$ \\
\hline HDL & $164(91.6)$ & $15 \quad(8.4)$ & $206(93.2)$ & $15 \quad(6.8)$ & $370(92.5)$ & $30(7.5)$ \\
\hline LDL & $131(73.2)$ & $48(26.8)$ & $152(68.8)$ & $69(31.1)$ & $283(70.8)$ & $117(29.2)$ \\
\hline
\end{tabular}


Sri Lanka Journal of Medicine Vol. 25 No.1 2015

Table 4. Mean fasting blood sugar and lipid levels of male and female students according to the BMI category and blood pressure levels

\begin{tabular}{|c|c|c|c|c|c|c|c|}
\hline \multirow{3}{*}{$\begin{array}{l}\text { Fasting } \\
\text { sugar(FBS) and } \\
\text { lipids (mg/dl) }\end{array}$} & \multicolumn{3}{|c|}{ BMI categories } & \multirow[b]{3}{*}{ Sig.* } & \multicolumn{2}{|c|}{ Blood pressure categories } & \multirow[b]{3}{*}{ Sig.** } \\
\hline & Underweight & Normal & Overweight & & Normal & $\begin{array}{l}\text { Pre-hypertension } \\
\text { \& elevated BP }\end{array}$ & \\
\hline & Mean(SD) & Mean (SD) & Mean (SD) & & Mean (SD) & Mean (SD) & \\
\hline \multicolumn{8}{|l|}{ Male $(n=179)$} \\
\hline FBS & $84.2(9.1)$ & $82.7 \quad(9.2)$ & $87.0(8.1)$ & $\mathrm{p}=0.225$ & $83.1 \quad(9.1)$ & $91.6(6.8)$ & $p=0.016$ \\
\hline Total cholesterol & $178.4(26.7)$ & $180.3(23.1)$ & $202.4(15.1)$ & $p<0.004$ & $180.4(23.9)$ & $205.2(22.1)$ & $p=0.025$ \\
\hline Triglycerides & $83.8(33.4)$ & $87.6(33.6)$ & $102.0(50.8)$ & $\mathrm{p}=0.257$ & $86.9(33.4)$ & $106.7(65.5)$ & $\mathrm{p}=0.455$ \\
\hline $\mathrm{HDL}$ & $52.4(10.7)$ & $47.2(10.0)$ & $43.6(7.9)$ & $\mathrm{p}=\mathbf{0 . 0 0 3}$ & $48.0(10.2)$ & $53.4(14.6)$ & $\mathrm{p}=0.370$ \\
\hline LDL & $107.5(24.0)$ & $115.1(24.1)$ & $139.9(17.4)$ & $\mathrm{p}<0.001$ & $114.3(24.8)$ & $130.4(21.3)$ & $\mathrm{p}=0.093$ \\
\hline $\begin{array}{l}\text { Total } \mathrm{CHO} / \mathrm{HDL} \\
\text { ratio }\end{array}$ & $3.5 \quad(1.1)$ & $3.9(1.0)$ & $4.8 \quad(0.7)$ & $\mathrm{p}<0.001$ & $3.9 \quad(1.1)$ & $4.1 \quad(1.1)$ & $\mathrm{p}=0.701$ \\
\hline \multicolumn{8}{|l|}{ Female $(n=221)$} \\
\hline FBS & $80.8(9.3)$ & $79.9 \quad(8.5)$ & $81.9(9.6)$ & $\mathrm{p}=0.649$ & $79.8(8.5)$ & $82.9(9.7)$ & $\mathrm{p}=0.230$ \\
\hline Total cholesterol & $189.6(21.4)$ & $185.9(27.3)$ & $201.9(16.8)$ & $\mathrm{p}=0.101$ & $185.4(25.9)$ & $209.8(22.9)$ & $\mathrm{p}<0.001$ \\
\hline Triglycerides & $91.3(25.1)$ & $90.1(29.7)$ & $97.1(32.6)$ & $\mathrm{p}=0.712$ & $90.0(29.1)$ & $98.5(32.2)$ & $\mathrm{p}=0.308$ \\
\hline HDL & $51.5 \quad(9.7)$ & $50.3(9.8)$ & $48.2(8.2)$ & $\mathrm{p}=0.605$ & $50.0(9.7)$ & $53.8(8.9)$ & $\mathrm{p}=0.104$ \\
\hline LDL & $119.9(20.8)$ & $117.9(23.1)$ & $134.4(12.9)$ & $p=0.039$ & $117.6(22.2)$ & $137.6(19.9)$ & $\mathrm{p}=\mathbf{0 . 0 0 1}$ \\
\hline $\begin{array}{l}\text { Total } \mathrm{CH} \\
\text { ratio }\end{array}$ & $3.7(0.6)$ & $3.8 \quad(0.8)$ & $4.3 \quad(0.8)$ & $\mathrm{p}=0.078$ & $3.8 \quad(0.8)$ & $4.0 \quad(0.9)$ & $\mathrm{p}=0.304$ \\
\hline
\end{tabular}

*F- test was performed to test the level of significance. Significance of between categories was tested using Bonferroni test.

** $\mathrm{t}$ - test was performed to test the level of significance.

A significant difference for LDL was seen between BMI categories $(\mathrm{p}<0.039)$ among female students.

The mean values of FBS, lipid levels and total $\mathrm{CHO} / \mathrm{HDL}$ ratio were higher among students with pre-hypertension and elevated blood pressure than among students with normal blood pressure in both sexes (Table 4).

The mean TC and LDL values were higher among the insufficiently physically active male students than physically active students and mean HDL value was higher among the physically active students (Table 5). The mean FBS, TC, TG and LDL levels were higher among both sexes who consumed optimal diets (Table 5).

\section{Discussion}

The prevalence of CVD risk factors is mostly behaviour related, hence influenced by lifestyle. Changing lifestyles with urbanization often lead to an increase in CVD risk associated behaviours and lead to the occurrence of biological risk factors. The present study showed that, $33 \%$ of females and $22.3 \%$ of males had TC levels above $200 \mathrm{mg} / \mathrm{dl}$, the normal level. It also showed that $8.4 \%$ of male and $6.8 \%$ of female students had HDL levels below normal.There were $26.8 \%$ of males and $31.2 \%$ females having LDL levels which were above the normal. 
Table 5. Mean fasting blood sugar and lipid levels of male and female students according to the level of physical activity and dietary quality

\begin{tabular}{|c|c|c|c|c|c|c|}
\hline \multirow{3}{*}{$\begin{array}{l}\text { Fasting blood sugar } \\
\text { (FBS) and blood } \\
\text { lipids (mg/dl) }\end{array}$} & \multicolumn{2}{|c|}{ Level of physical activities } & \multirow[b]{3}{*}{ Sig.* } & \multicolumn{2}{|l|}{ Quality of diet } & \multirow[b]{3}{*}{ Sig.* } \\
\hline & $\begin{array}{l}\text { Physically } \\
\text { active }\end{array}$ & $\begin{array}{l}\text { Insufficiently } \\
\text { Physically active }\end{array}$ & & Optimal & Suboptimal & \\
\hline & Mean(SD) & Mean (SD) & & Mean (SD) & Mean (SD) & \\
\hline \multicolumn{7}{|l|}{ Male $(n=179)$} \\
\hline FBS & $83.6 \quad(8.4)$ & $83.0 \quad(10.6)$ & $\mathrm{p}=0.713$ & $84.9 \quad(9.0)$ & $82.7 \quad(9.1)$ & $p=0.126$ \\
\hline Total cholesterol & 180.8 & 182.6 & $\mathrm{p}=0.640$ & 181.7 (27.7) & $181.3(22.6)$ & $\mathrm{p}=0.928$ \\
\hline Triglycerides & $89.4(33.3)$ & $84.3 \quad(38.5)$ & $\mathrm{p}=0.385$ & $91.9(28.9)$ & $85.6(37.6)$ & $\mathrm{p}=0.221$ \\
\hline HDL & $48.5(10.2)$ & $47.7 \quad(10.8)$ & $\mathrm{p}=0.626$ & $48.1(11.2)$ & $48.3(10.0)$ & $\mathrm{p}=0.925$ \\
\hline LDL & 113.9 (25.3) & 116.9 & $\mathrm{p}=0.436$ & $115.5(28.3)$ & $114.9(23.0)$ & $\mathrm{p}=0.848$ \\
\hline $\begin{array}{l}\text { Total CHO/HDL CHC } \\
\text { ratio }\end{array}$ & $3.9 \quad(1.0)$ & $4.0 \quad(1.1)$ & $\mathrm{p}=0.361$ & $3.9 \quad(1.2)$ & $3.9 \quad(1.0)$ & $\mathrm{p}=0.997$ \\
\hline \multicolumn{7}{|l|}{ Female $(n=221)$} \\
\hline FBS & $80.9 \quad(8.7)$ & $79.1 \quad(8.4)$ & $\mathrm{p}=0.125$ & $80.8 \quad(8.5)$ & (8.6) & $p=0.352$ \\
\hline Total cholesterol & $189.1(28.3)$ & 184.9 & $\mathrm{p}=0.242$ & $187.6(21.1)$ & 187.0 & $p=0.866$ \\
\hline Triglycerides & 90.2 (28.7) & $91.2(30.2)$ & $\mathrm{p}=0.797$ & $88.7(29.8)$ & $91.6(29.1)$ & $\mathrm{p}=0.466$ \\
\hline HDL & $51.3(10.4)$ & $49.0 \quad(8.6)$ & $\mathrm{p}=0.075$ & $49.3 \quad(8.6)$ & $50.9 \quad(10.2)$ & $\mathrm{p}=0.220$ \\
\hline LDL & 120.2 & 117.7 (22.5) & $\mathrm{p}=0.431$ & 121.3 & $117.8(23.7)$ & $\mathrm{p}=0.248$ \\
\hline $\begin{array}{l}\text { Total CHO/HDL CHC } \\
\text { ratio }\end{array}$ & $(0.8)$ & $3.9 \quad(0.8)$ & $\mathrm{p}=0.343$ & $3.9 \quad(0.9)$ & $3.7 \quad(0.7)$ & $\mathrm{p}=0.101$ \\
\hline
\end{tabular}

** $\mathrm{t}$ - test was performed to test the level of significance.

The relatively high prevalence of dyslipidaemia observed in the present study could be due to multiple factors, including urbanized lifestyle among school going adolescents. Studies done in other urban settings also show comparable findings.

In a study conducted among 637 adolescent school boys studying in grades 10 to 13 in Colombo, Negambo and Kurunegala, the mean total cholesterol level was within the reference rage $(158 \pm 27.2 \mathrm{mg} / \mathrm{dl})$ but $16.5 \%$ had values more than $185 \mathrm{mg} / \mathrm{dl}$. This study also identified that $21.9 \%$ of the adolescents had high LDL levels, and $27.3 \%$ had low HDL levels. This study also noted that there was a significant association between high serum cholesterol and high BMI levels ${ }^{(9)}$. Both studies show relatively high levels of TC and LDL and low levels of HDL. The difference shown in some parameters of lipid profile may be due to the differences in study settings, study population and the time of the study.

Sri Lankan adolescents in both these studies reported higher serum cholesterol levels than adolescents in the USA. Populationbased data in USA from NHANES III (1988-1994) indicate that among children and adolescents (4 to 19 years old), the mean TC was $165 \mathrm{mg} / \mathrm{dl}$. Females had significantly higher mean TC and LDL than males. Approximately $10 \%$ of adolescents (12 to 19 years old) had TC levels >200 $\mathrm{mg} / \mathrm{dL}{ }^{(17)}$. However, the data come from over a decade apart. Both regional differences and the changes in lifestyles over the years could be the reasons for these differences.

Growth and development during childhood and adolescence and the different developmental pattern among different sexes may have an impact on total cholesterol 
values of males and females. The higher percentages of total cholesterol and other lipid levels among female adolescents could be explained to some extent by the difference of growth and sexual maturity at the age of 14 to 15 years.

Cholesterol levels track over time, which means the children with high lipid levels are likely to become adults with high levels ${ }^{(18)}$. In a study done in the district of Colombo among an adult population, $30.5 \%$ of males and $24.5 \%$ of females had TC levels above normal and $27.8 \%$ males and $22.1 \%$ of females had high LDL levels. Nineteen percent of males and $10.3 \%$ females had high TG levels and $14.1 \%$ of males and $18.6 \%$ females had low HDL levels ${ }^{(11)}$. The main difference in this study with the current one is the higher level of lipids among the male cohort. Again, the differences in the time frames in the study could partly explain this. However, it may be interesting to observe if the same gender difference persists in the study cohort as they grow older.

Since adult cut off points for lipid levels had been used in the Colombo study, the two populations could be compared to some extent though there are some limitations. Findings of both studies, together strengthen the hypothesis that cholesterol levels track over time from adolescence to adulthood. Bogalusa data indicate that about $70 \%$ of children with elevated total cholesterol in childhood remained with elevated levels during young adulthood ${ }^{(19)}$.

Mean FBS, TC, TG and LDL values were higher among overweight students than in normal and underweight students in both sexes in the present study. This finding is comparable with the study of Athukorala et al. done in Colombo in 1990s (9) and also with the findings of a study done among adolescents between 12 to18 years in Taipei. The Taipei study showed that obese boys had a significantly higher glucose, TC, TG, HDL and LDL concentrations than nonobese adolescents ${ }^{(20)}$. A similar finding could be seen in the Québec Family Study done among adolescents. The study reports that TC, LDL, HDL, CHOL/HDL-C, TG and glucose concentrations are higher among overweight participants when compared to normal-weight participants ${ }^{(21)}$. In the present study, the mean values of FBS and lipid profile were higher among students with pre-hypertension and elevated blood pressure than those with normal blood pressure. Pre hypertension and elevated blood pressure was higher among overweight adolescents. This demonstrates the inter-related nature of the CVD risk factors.

The mean levels of FBS and blood lipid levels did not show any significant relationship with the quality of diet they eat. This relationship of diet and blood sugar and lipid levels may be due to the rapid body growth and nutrition demand of adolescents at this age.

One of the determinants of blood lipid levels is the family history of dyslipidaemia and it was not explored in this study. This was a limitation when interpreting blood lipid levels in the present study.

\section{Conclusions}

The prevalence of high FBS levels was very low but the prevalence of dyslipidaemia was high among students of both sexes. A BMI of overweight category and high blood pressure were associated with dyslipidaemia. The level of physical activity was also significantly related to the blood lipid levels among adolescents. However, the quality of 
diet and blood lipid levels did not show an association in the study.

\section{Acknowledgements}

I acknowledge with gratitude, the support of Dr. C. Arambepola and Professor S Siverkanesan. Parents and students who participated in the study are acknowledged for their cooperation in data collection.

\section{Conflict of interest and financial disclosure: None}

\section{References}

1. Annual Health Bulletin -2012. Ministry of Health, Sri Lanka. 2012.

2. World Health Organization. Neglected Global epidemic: three growing threats, The World Health Report. Geneva:WHO, 2003.

3. Hill D, Nishda C and James WPT. A Life course approach to diet, nutrition and prevention of chronic diseases. Public Health Nutrition 2004; 7(1A): 101-112

4. World Health Organization. Life course perspectives on Coronary Heart Disease, Stroke and Diabetes, Key issues and implications for policy and research. Summery report of a meeting of experts 24 May 2001. Aging and life course department of non communicable diseases prevention and promotion Geneva: WHO, 2001.

5. Berenson GS, Srinivasan SR, Bao W, Newman WP, Tracy RE, Wattgney WA. Association between multiple cardiovascular risk factors and atherosclerosis in children and young adults. New England Journal of medicine 1998; 338: 650-1656.

6. Assmann G, Schulte H, Funke H and Eckardstein A.. The emergence of triglycerides as a significant independent risk factor in coronary artery disease. Eur Heart J 1998; 19: 8-14.
7. Bao W, Srinivasan SR and Berenson GS. Persistent elevation of plasma insulin levels is associated with increased cardiovascular risk in children and young adults. The Bogalusa Heart Study. Circulation, 1996; 93(1): 54-59.

8. Mendis S and Ekanayake EM. Prevalence of coronary heart disease and cardiovascular risk factors in middle aged males in a defined population in central Sri Lanka. Int J Cardiol. 1994; 46(2):135-42.

9. Athukorala TMS, de Silva LDR and Jayasinghe KSA. Lipid profile, anthropometry and dietary habits of adolescents school boys in Sri Lanka. Asia Pacific J Clinical Nutrition. 1997; 6(3): 207213.

10. Lwanga SK and Lemeshow S. Sample size determination in health studies: A practical manual, Geneva, WHO. 1991.

11. Arambepola C. Abdominal obesity and its association with selected risk factors of coronary heart disease in an adult population in the district of Colombo, Thesis submitted for the degree of Doctor of Medicine in Community Medicine, Post Graduate Institute of Medicine, Colombo, 2004.

12. IPAQ Data Management Group, International physical activity questionnaire, 2002. [on line] Available from http:// www.ipaq.ki.se

13. World Health Organization, Physical Status: The Use and Interpretation of Anthropometry - Report of a WHO Expert Committee, Geneva: WHO.1995. Technical Report Series No. 854, 306.

14. American Heart Association, Recommendations for Blood Pressure Measurement in Humans and Experimental Animals Part 1: Blood Pressure Measurement in Humans: A Statement for Professionals from the Subcommittee of Professional and Public Education of the American Heart Association Council on High Blood Pressure Research. AHA Scientific Statement. 2005. [on 
line].Available from http//hype.ahajournals.org.

15. National High Blood Pressure Education Program Working Group on High Blood Pressure in Children and Adolescents, The Fourth Report on the Diagnosis, Evaluation, and Treatment of High Blood Pressure in Children and Adolescents. Pediatrics 2004; 114 (2) : 555-576

16. American Heart Association, Guidelines for primary prevention of Atherosclerotic Cardiovascular Diseases beginning in childhood. Circulation 2003;107: 1562-1566.

17. American Heart Association, Primary Prevention of Cardiovascular Disease in Nursing Practice: Focus on Children and Youth: A Scientific Statement. Circulation 2007; 116: 344-357.

18. American Heart Association, Cardiovascular Health in Childhood: A Statement for Health Professionals from the Committee on Atherosclerosis, Hypertension, and Obesity in the Young (AHOY) of the Council on Cardiovascular Disease in the Young. Circulation. 2002; 106:143.

19. Webler LS, Srinivasan SR, Wattigney WA and Berenson GS. Tracking of serum lipids and lipoproteins from childhood to adulthood: the Bogalusa Heart Study. American Journal of Epidemiology 1991; 133: 884-899

20. Chu NF, Rimm EB, Wang JD, Liou SH and Shieh SM. Clustering of cardiovascular disease risk factors among obese schoolchildren: the Taipei Children Heart Study. American Journal of Clinical Nutrition 1998; 67: 1141-1146

21. Katzmarzyka PT, Tremblayb A, Perusseb L, Despresc JP and Bouchardd C. The utility of the international child and adolescent overweight guidelines for predicting coronary heart disease risk factors. Journal of clinical epidemiology 2003; 56(5): 456462 